Brazilian Journal

of Chemical

ISSN 0104-6632

Printed in Brazil

Engineering

www.scielo.br/bjce

Vol. 35, No. 03, pp. 1039-1050, July - September, 2018

dx.doi.org/10.1590/0104-6632.20180353s20170382

\title{
PYROLYSIS KINETICS OF HULLESS BARLEY STRAW USING THE DISTRIBUTED ACTIVATION ENERGY MODEL (DAEM) BY THE TG/DTA TECHNIQUE AND SEM/XRD CHARACTERIZATIONS FOR HULLESS BARLEY STRAW DERIVED BIOCHAR
}

\author{
Jianghong Zhang ${ }^{1}$, Bing Huang ${ }^{2, *}$, Liang $\mathrm{Chen}^{2}$, Jiayao $\mathrm{Du}^{2}$, Wei $\mathrm{Li}^{1}$ and \\ Zhuanxi $\mathrm{Luo}^{3}$ \\ ${ }^{1}$ Faculty of Science, Kunming University of Science and \\ Technology, Kunming 650100, China; \\ ${ }^{2}$ Faculty of Environmental Science and Engineering, Kunming University of \\ Science and Technology, Kunming 650100, China; \\ ${ }^{3}$ Key Laboratory of Urban Environment and Health, Institute of Urban \\ Environment, Chinese Academy of Sciences, Xiamen 361021, China.
}

(Submitted: July 18, 2017; Revised: November 9, 2017; Accepted: November 12, 2017)

\begin{abstract}
The pyrolysis kinetics of hulless barley straw at different heating rates of 5, 10, 15, 20 and $30{ }^{\circ} \mathrm{C} / \mathrm{min}$ were investigated via thermogravimetry, and the activation energy distribution $E$ and pre-exponential factor $k_{0}$ were calculated using the Distributed Activation Energy Model (DAEM) from thermogravimetric analysis (TGA) curves, and characterizations of pyrolysis product of biochar were analyzed by techniques of scanning electron microscopy (SEM) and X-ray diffraction (XRD). The pyrolysis process consisted mainly of the dehydration stage $\left(50-150^{\circ} \mathrm{C}\right)$, the active pyrolysis stage $\left(200-400^{\circ} \mathrm{C}\right)$ and the passive pyrolysis stage $\left(400-800{ }^{\circ} \mathrm{C}\right)$. The $E$ ranged from 73.45 to $214.11 \mathrm{~kJ} / \mathrm{mol}$ within the conversion rate range of $0.10-0.55$, and changed from 214.11 to $141.55 \mathrm{~kJ} / \mathrm{mol}$ within the conversion rate range of $0.55-0.90$, and the average value of $E$ was $172.23 \mathrm{~kJ} / \mathrm{mol}$. The values of $k_{0}$ changed greatly with $E$ values at different mass conversion. The wide $E$ and $k_{0}$ distributions obtained from the kinetic analysis are attributed to the complex chemical reactions of pyrolysis. The structure of biochar was degraded or ruptured due to the increase in temperature. The XRD analysis confirmed that the biochar was amorphous, dominated by disordered graphitic crystallites.
\end{abstract}

Keywords: Hulless barley straw; Thermogravimetric analysis; Distributed activation energy model; Pyrolysis kinetics.

\section{INTRODUCTION}

It is well documented that biomass can be converted to various chemicals, biofuels, and solid biochar using modern processes. Biomass is currently increasingly perceived as a renewable resource rather than as an organic solid waste (Liu et al., 2017). Hulless barley is one of the most extensively planted crops in the

*Corresponding author. E-mail address: binhuang_ok@163.com 
Qinghai Tibetan Plateau of China. In China's Tibet alone, the yield of Hulless barley reached $680542 \mathrm{t}$ in 2014 (Statistical Bureau of Tibet Autonomous Region, 2015). Subsequently, harvesting and processing of hulless barley result in considerable quantities of crop straw, hulless barley straw, which are usually burned (incineration) in the open, emitting $\mathrm{CO}_{2}, \mathrm{NO}_{x}$, heavy metals, fine particles, and persistent organic pollutants, or by landfilling, producing leachate with various contaminants such as heavy metals, toxic organic compounds, $\mathrm{NH}_{4}^{+}$, and $\mathrm{NO}_{3}^{-}$leading to serious air, soil and groundwater pollutions. However, when properly handled, hulless barley straw becomes an abundantly available resource. Therefore, the proper and efficient treatment of crop straw has important significance to maintain environmental quality and for sustainable development (Liu et al., 2017).

Among the methods (microbially mediated transformations and thermochemical route) for the conversion of waste biomass into biofuels or chemical feedstocks, the thermochemical route (pyrolysis, gasification and hydrothermal liquefaction) is one of the prospective approaches. Pyrolysis, as an environmentally friendly and cost-effective technology for biomass conversion, has several advantages over the methods of incineration and landfilling because of its low energy consumption (only approximately $10 \%$ of the energy content of biomass is consumed for the pyrolysis itself), and the harmful gas emission in biomass pyrolysis is remarkably weaker than that in incineration. Therefore, in the past few years, pyrolysis has attracted growing interest as a promising versatile platform to convert biomass into valuable resources, and the number of scientific journal papers regarding biomass pyrolysis published per year increases rapidly, and has been thoroughly reviewed (Sharma et al., 2015; Anca-Couce, 2016; Dilks et al., 2016; Hassan et al., 2016; Kan et al., 2016; Patel et al., 2016; Tripathi et al., 2016; Zhang et al., 2016; Chiaramonti et al., 2017; Dhyani \& Bhaskar, 2017; Li \& Jiang, 2017; Liu et al., 2017; Murillo et al., 2017; Wang et al., 2017; Zeng et al., 2017).

Carbonaceous feedstock pyrolysis is the thermal decomposition of raw materials in the absence of oxygen into gaseous products (mainly $\mathrm{CO}_{2}, \mathrm{CO}, \mathrm{H}_{2}$, $\mathrm{CH}_{4}, \mathrm{C}_{2} \mathrm{H}_{2}, \mathrm{C}_{2} \mathrm{H}_{4}, \mathrm{C}_{2} \mathrm{H}_{6}$, etc.), liquid products (tar, highmolecular-weight hydrocarbons and water) and solid products (biochar). The pyrolysis process, based on the heating rate and reaction time, can be categorized into three types: slow, fast, and flash pyrolyses (Babu,
2008). The yields and properties of the bio-oil, biochar, and gas are influenced by many parameters, including vapor residence time, temperature, and heating rate. In general, with a low reaction temperature, a slow heating rate, and a long vapor residence time, the pyrolysis produces mainly biochar, while high temperature and heating rate and long vapor residence time increase gas yields. Moderate temperature, high heating rate, and short vapor residence time are beneficial for higher pyrolysis oil yields (Demirbas, 2004; Liu et al., 2017). In slow pyrolysis, lower heating rate (approximately 5-7 K/min) and longer vapor residence times (more than $1 \mathrm{~h}$ ) provide a suitable ambience and sufficient time for the secondary reactions to complete. Moreover, longer vapor residence time allows the vapors produced during the secondary reactions to be removed. This ultimately results in the formation of solid carbonaceous biochar.

Biochar is a solid carbon-rich by-product (typically more that $60 \%$ carbon) of thermal stabilization of biomass or any other organic matter. Biochar is mainly composed of aromatic hydrocarbons, simple carbon substances, or carbon with graphene structure, exhibiting better biological stability and thermostability than the precursor biomass. The microporous structure of the biochar and high carbon content makes it useful for several industrial applications. In agriculture it is used to upgrade the soil quality. Addition of biochar to the soil will increase the rate of carbon sequestration in soil, slowing down the rate of decomposition of nutrients from soil and, hence, finally enhancing the soil quality (Lehmann and Joseph, 2009; Atkinson et al., 2010; Uchimiya et al., 2011; Abdel-Fattah et al., 2015; Hansen et al., 2015; Qambrani et al., 2017). In the purification industry, biochar is used to remove heavy metals such as $\mathrm{Cr}, \mathrm{Cd}$, $\mathrm{Ni}, \mathrm{Hg}$ and $\mathrm{Pb}$. etc., and also for textile dye removal. In power generation biochar can be used as a fuel because biochar contains a high carbon percentage (Yip et al., 2010; Tripathi et al., 2016; Qambrani et al., 2017), and more importantly, the easily tuned surface functionality and porosity make biochar a promising platform to synthesize many carbon-based functional materials (Liu et al., 2015).

Thermogravimetry (TG) is a convenient technique for studying the degradation mechanism and for the determination of the kinetic parameters of pyrolysis and other thermochemical conversion processes (Carrier et al., 2011; White et al., 2011; Anca-Couce, 2016; Dhyani \& Bhaskar, 2017; Wang et al., 2017). Kinetic analysis is very important for designing and 
establishing efficient, safe and reasonable processes. Kinetic parameters obtained are necessary for the prediction of reaction behaviour, and the optimization of the pyrolysis process, so that chemicals or bio-energy can be produced. However, the multiscale complexity of the biomass structures and reactions involved in the pyrolysis process makes the investigation of pyrolysis mechanisms very difficult.

Generally, the chemical mechanism for biomass pyrolysis can be divided into the mechanisms of the three components of cellulose, hemicellulose, and lignin, which mainly depend on the vapor residence time, heating rate, temperature, reactor type, and particle size (Liu et al., 2017). Macroscopic kinetic modeling is often used to simulate the thermodegradation rates of feedstocks or to predict the formation rates of products during biomass pyrolysis, providing valuable information for reactor design and process optimization for biomass pyrolysis. With the development of kinetic theories and computer technologies, several macroscopic kinetic modeling methods with comprehensive mechanism schemes, such as the Distributed Activation Energy Model (DAEM), isoconversional method, lumped kinetic model involving the detailed evolution pathways of products, chemical percolation devolatilization model and kinetic Monte Carlo model, have been developed (Wang et al., 2017). Compared with common modelfitting methods DAEM can simulate mass loss across the overall conversion process with a much higher fitting precision. DAEM assumes that pyrolysis occurs through numerous independent parallel reactions with different activation energies, and the activation energy distribution of these reactions can be described by a continuous function. DAEM does not require a priori assumptions and mathematical model fitting for obtaining the kinetic parameters, only requiring a set of experimental data obtained with three different heating profiles, and has been widely used due to its simplicity and accuracy (Miura,1995; Miura et al.,1998; Cai et al., 2014; Soria-Verdugo et al., 2015).

Although, there are a number of studies on the pyrolysis of agricultural by-products, the significant physicochemical processes associated with the thermal degradation of biomass and their mechanisms are not understood in many important features up to now. To date, there is no reported work regarding the pyrolysis of hulless barley straw using DAME.

The main objective of the present study is to investigate the pyrolysis of hulless barley straw by thermogravimetry (TG) at different heating rates of 5 , $10,15,20$ and $30^{\circ} \mathrm{C} / \mathrm{min}$ from ambient temperature to $800{ }^{\circ} \mathrm{C}$ under a nitrogen atmosphere. Based on the TG curves, the activation energy and pre-exponential factor were calculated using the Distributed Activation Energy Model (DAEM) in order to elucidate the mechanism of pyrolysis of hulless barley straw, providing necessary information to fill the present technology gap on the pyrolysis of hulless barley straw. The characterizations of the pyrolysis product biochar were performed by the techniques of scanning electron microscopy (SEM) and X-ray diffraction (XRD).

\section{EXPERIMENTAL}

\section{Materials and methods}

\section{Materials}

The hulless barley straw biomass was obtained from the Napahai Plateau in Southwest China. The hulless barley straw was washed in deionizer water and dried in an oven at $110^{\circ} \mathrm{C}$, which was then smashed in a crushing machine (Yili QE-300, China) and passed through a 40 mesh sieve. The samples were pyrolysed in a stainless steel box with a lid under a nitrogen atmosphere at different target temperatures $\left(300,500\right.$ and $\left.700{ }^{\circ} \mathrm{C}\right)$ for $3 \mathrm{~h}$. The treated biochars were designated as QK-300, QK-500, QK-700.

The proximate analysis was performed according to ASTM standards D 1102, E871 and E872 for ash, moisture content and volatile matter, respectively. The fixed carbon is calculated as a difference. The ultimate analysis was performed using a Vario MICRO Cube (Elementar, Germany) elemental analyzer to determine the weight fractions of non-mineral major elements such as carbon $(\mathrm{C})$, hydrogen $(\mathrm{H})$, nitrogen $(\mathrm{N})$, and oxygen $(\mathrm{O})$, using $200 \mathrm{mg}$ oven dried samples in three replicates. For each analysis, the standard samples (i.e., sulfanilic acid and benzoic acid) were first analyzed to check the experimental error within \pm $0.1 \%$. The proximate and ultimate analyses of hulless barley straw biomass sample are listed in Table 1. Table 2 lists the ultimate analyses of hulless barley straw derived biochars.

\section{Thermogravimetric analysis}

The pyrolysis of hulless straw were performed on a TG 209 F3 Tarsus thermogravimetric analyzer (Netzsch, Germany). A thin layer of the sample (ca. $4 \mathrm{mg}$ ) was distributed evenly in a ceramic crucible to limit the thermal gradients in the conditions used. The instrument was previously calibrated for 
Table 1. Proximate and ultimate analysis of hulless barley straw biomass samples.

\begin{tabular}{lc}
\hline Property & Valuea \\
\hline Proximate analysis (wt\%) & \\
Moisture & $8.65 \pm 0.1$ \\
Volatile matter & $69.54 \pm 0.1$ \\
Ash & $9.56 \pm 0.1$ \\
Fixed carbon & $12.25 \pm 0.1$ \\
Ultimate analysis (wt\%) & \\
Carbon (C) & $39.5 \pm 0.1$ \\
Oxygen (O) & $20.75 \pm 0.1$ \\
Nitrogen $(\mathrm{N})$ & $2.04 \pm 0.1$ \\
Hydrogen $(\mathrm{H})$ & $6.48 \pm 0.1$ \\
\hline
\end{tabular}

${ }^{\mathrm{a}}$ Mean of three hulless barley straw samples with standard deviation

Table 2. Ultimate analyses of hulless barley straw derived biochars.

\begin{tabular}{lccc}
\hline $\begin{array}{l}\text { Ultimate } \\
\text { analysis }(\mathrm{wt} \%)^{\mathrm{b}}\end{array}$ & $\begin{array}{c}\text { Biochar } \\
\left(300^{\circ} \mathrm{C}\right)^{\mathrm{a}}\end{array}$ & $\begin{array}{l}\text { Biochar } \\
\left(500^{\circ} \mathrm{C}\right)\end{array}$ & $\begin{array}{c}\text { Biochar } \\
\left(700^{\circ} \mathrm{C}\right)\end{array}$ \\
\hline Carbon (C) & $40.24 \pm 0.1^{\mathrm{c}}$ & $41.11 \pm 0.1$ & $41.29 \pm 0.1$ \\
Oxygen (O) & $19.48 \pm 0.1$ & $15.27 \pm 0.1$ & $14.02 \pm 0.1$ \\
Nitrogen (N) & $2.04 \pm 0.1$ & $1.57 \pm 0.1$ & $1.33 \pm 0.1$ \\
Hydrogen (H) & $4.50 \pm 0.1$ & $4.12 \pm 0.1$ & $3.30 \pm 0.1$ \\
\hline
\end{tabular}

${ }^{\text {a }}$ Biochar produced at $300^{\circ} \mathrm{C}$, etc.

${ }^{\mathrm{b}}$ Dry basis.

${ }^{\mathrm{c}}$ Mean of three biochar samples with standard deviation.

the temperature under each thermal program. The pyrolysis experiments were performed at heating rates of $5,10,15,20$ and $30{ }^{\circ} \mathrm{C} / \mathrm{min}$ from ambient temperature to $800{ }^{\circ} \mathrm{C}$. During heating, mass and temperature of the sample were simultaneously and continuously recorded. In the pyrolysis experiments, $\mathrm{N}_{2}$ of ultra-high purity was passed through the TGA at a constant flow rate of $60 \mathrm{~mL} / \mathrm{min}$ to provide the inert gas environment and to sweep away the volatiles released. Every test was replicated at least twice. No significant differences were observed upon comparing the results of replicated tests.

\section{SEM and XRD analysis}

To observe the surface morphology pattern of hulless barley straw after pyrolysis, the biochar samples were imaged using scanning electron microscopy (SEM) (Hitachi S-4800, Japan).

XRD analysis was carried out to identify crystallographic structure in the biochar samples using a computer-controlled X-ray diffractometer (X'Pert Pro MPD, Dutch) equipped with a $\mathrm{Cu} \mathrm{K} \alpha$ radiation source operated at $65 \mathrm{kV}$ and $50 \mathrm{~mA}$.

\section{Kinetic analysis using DAEM}

The so-called distributed activation energy model (DAEM), originally developed by Vand (1943), assuming infinite number of irreversible first-order parallel reactions with different rate parameters occur simultaneously, where the difference in activation energies is represented by a distribution function $f(E)$, has been extensively used for analyzing the complex reactions occurring during the pyrolysis of different biomass fuels for understanding the reaction kinetics of the pyrolysis process (Sonobe and Worasuwannarak, 2008; Navarro et al., 2009; Shen et al., 2011; SoriaVerdugo et al., 2013; 2015; Cai et al., 2014; Chen et al., 2016; Bhavanam et al., 2015; Huang et al., 2017). Miura (1995) and Miura and Maki (1998) proposed two methods to estimate $f(E)$ and $k_{0}(E)$, a differential method and an integral method, from a set of three TG experiments at different heating rates, without assuming $k_{0}$ values and a functional form for $f(E)$. Although both methods are the same in principle, the integral method is more accurate and does not need a tedious differentiation step. All the reaction activation energies have the same $\mathrm{k}_{0}$ at the same conversion rate and the activation energy has a continuous distribution.

When the model is used to analyze biomass pyrolysis, the change in the total volatiles, $V$, with time, $t$, is given by (Miura and Maki, 1998):

$$
1-\frac{V}{V^{*}}=\int_{0}^{\infty} \exp \left(-k_{0} \int_{0}^{t} e-{ }^{E / R T} d t\right) f(E) d E
$$

where $V / V^{*}$ is the reacted fraction, $R$ the universal constant, $T$ the temperature for each devolatilization, $V^{*}$ is the effective volatile content, $V$ is the volatile content at temperature $T, k_{0}$ is the frequency factor corresponding to the $E$ value, and $f(E)$ is the normalized distribution curve of the activation energy that represents the difference in the activation energies of the many first-order irreversible reactions. Usually, the pre-exponential factor is considered to be a constant over the temperature range studied. Then Eq. (1) can be simplified to Eq. (2) (Miura, 1995; Miura and Maki, $1998)$. The $\Phi(E, T)$ function varies steeply with $E$ at a given temperature $T$ for the heating rate $\beta$.

$$
\begin{gathered}
1-\frac{V}{V^{*}}=\int_{0}^{\infty} \Phi(E, T) f(E) d E \\
\Phi(E, T)=\exp \left(\frac{-k_{0}}{\beta} \int_{0}^{T} e^{-E / R T} d T\right)
\end{gathered}
$$

where,

$$
1-\frac{V}{V^{*}}=\int_{0}^{\infty} \exp \left(\frac{-k_{0}}{\beta} \int_{0}^{T} e^{-E / R T} d T\right) f(E) d E
$$

In this simplified model, the Arrhenius equation can be described as follows: 


$$
\ln \frac{\beta}{T^{2}}=\ln \frac{k_{0}}{E}+0.6075-\frac{E}{R T}
$$

Equation (5) develops a linear relationship between $\ln \left(\beta / T^{2}\right)$ and $(1 / T)$ with the slope of $(-E / R)$. Miura and Maki (1998) proposed a procedure following the steps:

Measure and plot the devolatilization rate, $V / V^{*}$, as a function of the temperature, $T$, for the different heating rates, $\beta$

Plot $\ln \left(\beta / \mathrm{T}^{2}\right)$ versus $1 / T$ for the different heating rates at each devolatilization rate (Arrhenius plot).

For each $V / V^{*}$ in the Arrhenius plot, linearize the data of the different heating rates and obtain the activation energy $E$ and the pre-exponential factor $k_{0}$ from the slope and the intercept, respectively.

\section{RESULTS AND DISCUSSION}

\section{Thermogravimetric analysis}

The interpretation of derivative thermogravimetric (DTG) curves is often required as a prerequisite to extract preliminary and important thermophysical characteristics of materials. The main DTG peak is usually attributed to cellulose degradation, accompanied by a shoulder at lower temperature, which is related to hemicellulose degradation, and a tail at high temperature corresponding to lignin degradation (Carrier et al., 2011).

Figure 1 shows the thermogravimetric (TG) and derivative thermogravimetric (DTG) curves of hulless barley straw pyrolysis at different heating rates of 5 , $10,15,20$ and $30^{\circ} \mathrm{C} / \mathrm{min}$ from ambient temperature to $800^{\circ} \mathrm{C}$. The shape and area of the peaks (Figure 1) follow classical trends. It was found that with increasing heating rate, the TG curve shifted to higher temperature and the peak of the DTG curve became bigger. Below $150^{\circ} \mathrm{C}$, there was a small weight loss that represents the evaporation of moisture, corresponding to a peak in the DTG curves. The devolatilization of hulless barley straw starts at above $200{ }^{\circ} \mathrm{C}$ and it is completed by $600{ }^{\circ} \mathrm{C}$. There were three distinct stages of weight loss at the three different heating rates: a dehydration stage $\left(50-150^{\circ} \mathrm{C}\right)$, a second active pyrolysis stage $\left(200-400{ }^{\circ} \mathrm{C}\right)$, and a passive pyrolysis stage (400-800 $\left.{ }^{\circ} \mathrm{C}\right)$.

During stage $\mathrm{I}$, the small change in loss of the mass is attributed to the loss of water and light volatile compounds in the hulless barley straw samples. Stage II is characterized by a major mass loss, mainly from the decomposition of hemicellulose, cellulose and lignin, which is in the agreement with other biomass

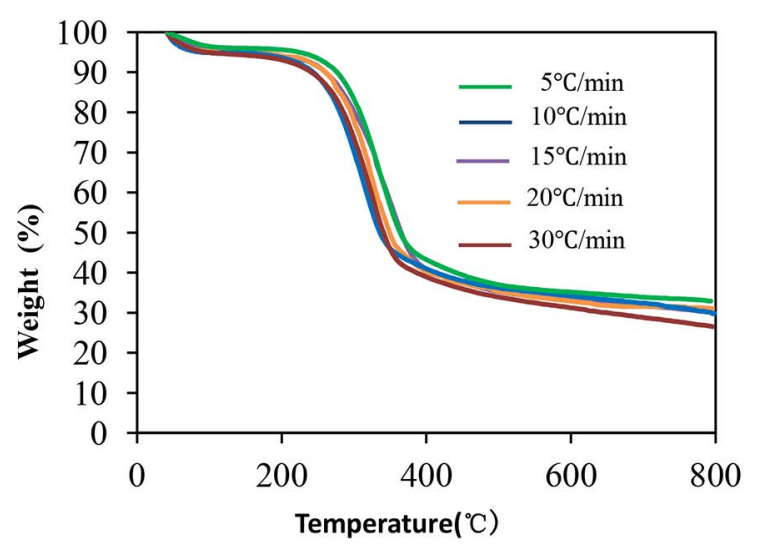

(a)

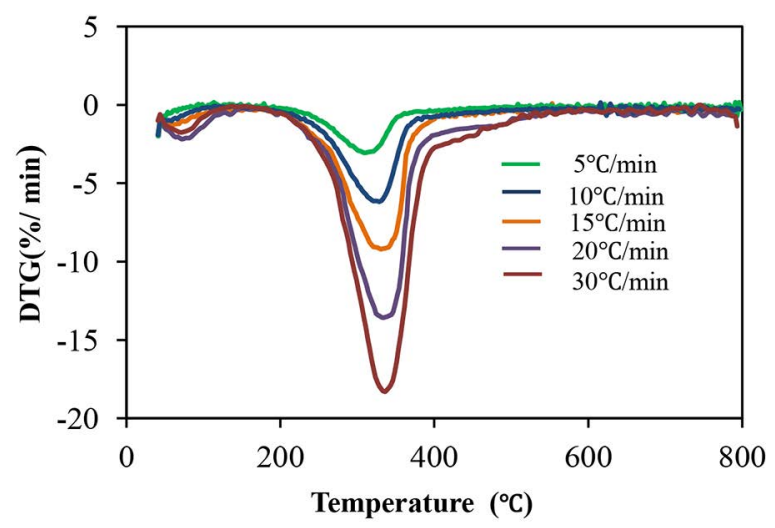

Figure 1. TG and DTG curves of hulless barley straw pyrolysis at different heating rates: (a): TG; (b): DTG

pyrolysis (Liu et al., 2017). TG curves (Figure 1a) of the hulless barley straw samples exhibited two mass loss steps. A peaks was observed in the DTG curves (Figure $1 \mathrm{~b}$ ), with the peak temperature at $340{ }^{\circ} \mathrm{C}$, and the rate of mass loss reached its maximum. In this stage, most of the organic materials were gradually released, resulting in a large loss of mass (more than $70 \%$ of total volatiles) and the formation of the main pyrolytic products. In stage III, the carbonaceous matter decomposed at a slow rate over a broad temperature range (Carrier et al., 2011).

The peak temperature, maximum rate of degradation and the residual weight after $800^{\circ} \mathrm{C}$ for all the biomasses at different heating rates are presented in Table 3. The TG curves showed that they shifted toward the right as the heating rate increased. It generally follows a nonisothermal pyrolysis process. It can be seen from Figure $1 \mathrm{~b}$ that the maximum rate of decomposition tends to increase at higher heating rate because there is more thermal energy to facilitate better heat transfer between the surroundings and the insides of the samples; the higher heating rates provided less time for reactions to form more volatile products. The temperatures corresponding to the maximum mass loss all increased, which were $314,329,331,333$ and 
$336^{\circ} \mathrm{C}$ at heating rates of $5,10,15,20$ and $30^{\circ} \mathrm{C} / \mathrm{min}$, respectively.

\section{Kinetic analysis}

The thermal decomposition reactions of biomass involve a large number of reactions in parallel and in series. The kinetic analysis includes recording of weight loss curves at different heating rates in order to deduce the dependence of the kinetic parameters on conversion level. In this work a DAEM is evaluated from the set of three experimental runs at each different heating rate $\left(5,10,15,20\right.$ and $\left.30^{\circ} \mathrm{C} / \mathrm{min}\right)$. The $V / V^{*}$ values with respect to the temperatures $(T)$ are calculated from the TGA experimental data. From the data obtained from the $V / V^{*}$ vs. $T$ relationships at different heating rates, the values of $\beta / T^{2}$ at selected $V / V^{*}$ values $(0.1-0.9)$ are calculated. These values are plotted in the form of $\ln \left(\beta / T^{2}\right)$ vs. $1 / T$ plot at the selected values of $V / V^{*}$. The $E$ and $k_{0}$ values are determined from the slope and the intercept of the Arrhenius plots at different $V / V^{*}$ values using the relationship in Eq. (5). The activation energies calculated by the DAEM method are listed in Table 3.

Table 3. Thermal degradation of hulless barley straw during the pyrolysis process at different heating rates.

\begin{tabular}{cccc}
\hline $\begin{array}{c}\text { Heating rates } \\
\left({ }^{\circ} \mathrm{C} / \mathrm{min}\right)\end{array}$ & $\begin{array}{c}\text { Maximum rate } \\
\text { of degradation } \\
-\mathrm{DTG}(\mathrm{mg} / \\
\mathrm{min})\end{array}$ & $\mathrm{T}_{\text {peak }}\left({ }^{\circ} \mathrm{C}\right)$ & $\begin{array}{c}\text { Residual } \\
\text { weight }(\%) \\
\text { after } 800{ }^{\circ} \mathrm{C}\end{array}$ \\
\hline 5 & 3.04 & 314 & 32.91 \\
10 & 6.15 & 329 & 29.76 \\
15 & 10.24 & 331 & 30.26 \\
20 & 13.37 & 333 & 30.07 \\
30 & 18.36 & 336 & 26.63 \\
\hline
\end{tabular}

Figure 2 shows the relationships of $V / V^{*}$ vs. $T$ for hulless barley straw measured at heating rates $\beta$ of 5 , $10,15,20$ and $30^{\circ} \mathrm{C} / \mathrm{min}$, these being representative plots for the main stage of mass loss. Figure 3 shows the Arrhenius plots of $\ln \beta / T^{2}$ vs. $1 / T$ at selected $V / V^{*}$ values for hulless barley straw, showing that all plots had fairly high linear correlation coefficients greater than 0.90 (Table 4), which meant that the linear fitting equation was in accord with the rule of weight losing during the hulless barley straw pyrolysis, indicating that for different $V / V^{*}$, the volatiles conversion during the thermal decomposition of the hulless barley straw can be described by a set of parallel first-order reactions. The kinetic parameters of the thermal reactions significantly affect their reactivity and sensitivity. The activation energy $E$ is defined as the minimum amount of energy required for the reagents to react; therefore, higher $E$ values mean slower overall reaction rates.

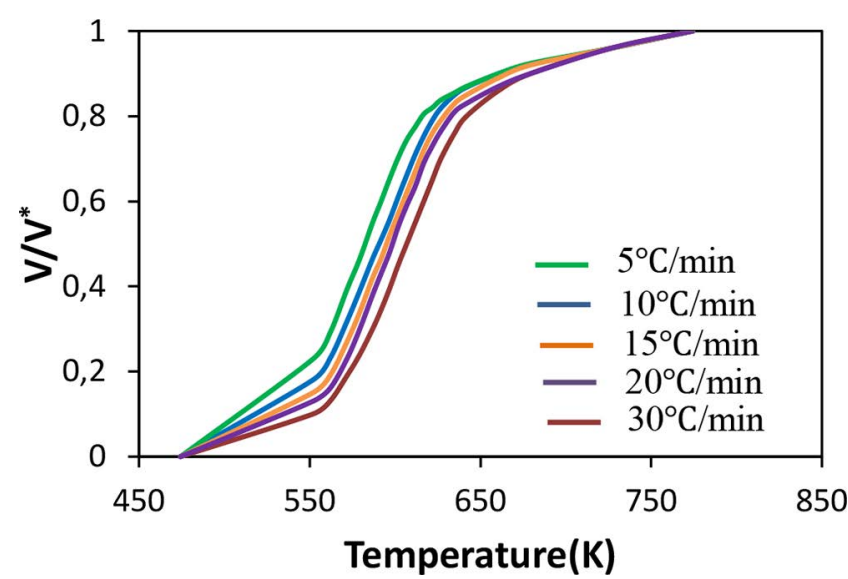

Figure 2. $\mathrm{V} / \mathrm{V}^{*}$ vs. T relationship measured at $\beta=5,10,15,20$ and $30^{\circ} \mathrm{C} / \mathrm{min}$ for hulless barley straw.

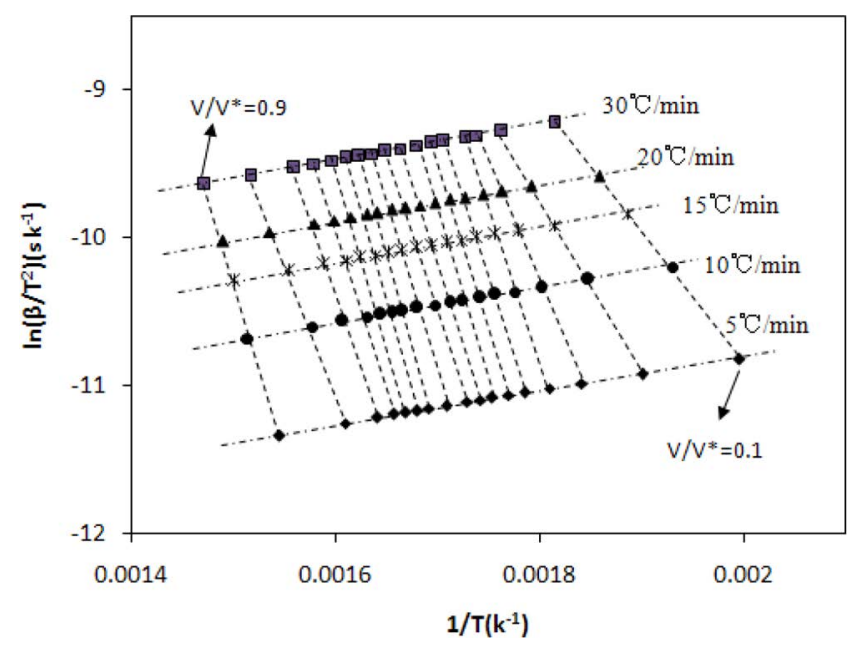

Figure 3. Arrhenius plot of $\ln \beta / \mathrm{T}^{2}$ vs. $1 / \mathrm{T}$ at selected $\mathrm{V} / \mathrm{V}^{*}$ values for hulless barley straw.

Therelationship between $V / V^{*}$ vs. Ecould beobtained by plotting the $V / V^{*}$ value against the corresponding $E$ values, as shown in Figure 4. The activation energy revealed fluctuation at different conversion rates $V / V^{*}$. Table 4 lists the activation energies and preexponential factors obtained at different conversion rates. The $E$ ranged from 73.45 to $214.11 \mathrm{~kJ} / \mathrm{mol}$ in the conversion rate range of $0.10-0.55$, and changed from 214.11 to $141.55 \mathrm{~kJ} / \mathrm{mol}$ in the conversion rate range of $0.55-0.90$, and the average value of $E$ was 172.23 $\mathrm{kJ} / \mathrm{mol}$. The values of $k_{0}$ changed greatly with $E$ values at different mass conversions. It is obvious that the activation energy of hulless barley straw pyrolysis is widely distributed, and each conversion rate has a corresponding individual activation energy during the hulless barley straw pyrolysis, and the $k_{0}$ value cannot be assumed to be a constant for the pyrolysis of hulless barley straw. Chen et al. (2016) used DAEM to study the kinetics of coffee industrial residue pyrolysis, concluding that the $E$ values changed from 163.42 to 
Table 4. The activation energies and pre-exponential factors obtained at different conversion rates.

\begin{tabular}{cccc}
\hline $\boldsymbol{V} / \boldsymbol{V}^{*}$ & $\boldsymbol{E} / \mathrm{kJ} / \mathrm{mol}$ & $\boldsymbol{k}_{0} / \mathrm{s}^{-1}$ & $\mathrm{R}^{2}$ \\
\hline 0.10 & 73.45 & $5.32 \times 10^{5}$ & 0.998 \\
0.15 & 97.92 & $7.31 \times 10^{7}$ & 0.999 \\
0.20 & 137.49 & $3.03 \times 10^{11}$ & 0.999 \\
0.25 & 172.04 & $3.92 \times 10^{14}$ & 0.999 \\
0.30 & 180.17 & $1.46 \times 10^{15}$ & 0.997 \\
0.35 & 188.59 & $6.33 \times 10^{15}$ & 0.999 \\
0.40 & 193.02 & $1.11 \times 10^{16}$ & 0.999 \\
0.45 & 208.78 & $2.73 \times 10^{16}$ & 0.98 \\
0.50 & 211.05 & $3.91 \times 10^{16}$ & 0.985 \\
0.55 & 214.11 & $4.49 \times 10^{16}$ & 0.997 \\
0.60 & 209.36 & $7.67 \times 10^{16}$ & 0.996 \\
0.65 & 206.09 & $2.85 \times 10^{16}$ & 0.993 \\
0.70 & 196.13 & $2.78 \times 10^{15}$ & 0.997 \\
0.75 & 178.78 & $6.15 \times 10^{13}$ & 0.995 \\
0.80 & 172.63 & $1.13 \times 10^{13}$ & 0.996 \\
0.85 & 146.72 & $1.68 \times 10^{12}$ & 0.996 \\
0.90 & 141.55 & $1.18 \times 10^{11}$ & 0.998 \\
Average & 172.23 & & \\
\hline
\end{tabular}

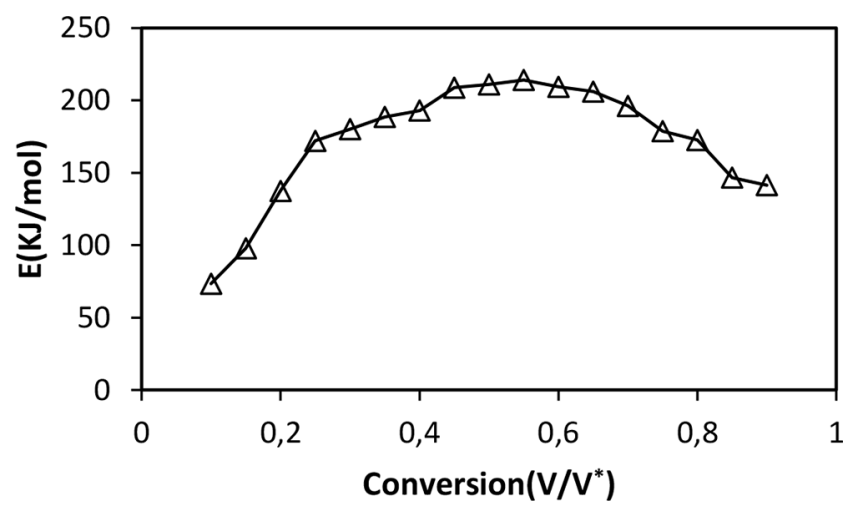

Figure 4. Activation energy $\mathrm{E}$ vs. conversion rate $\mathrm{V} / \mathrm{V}^{*}$ estimated from the Arrhenius plot

$239.49 \mathrm{~kJ} / \mathrm{mol}^{-1}$ (average $187.86 \mathrm{~kJ} / \mathrm{mol}^{-1}$ ), Sonobe and Worasuwannarak (2008) used DAEM to study several agricultural residue (rice straw, rice husk, corncob and cellulose) pyrolyses and found an $E$ spread from 120 to $250 \mathrm{~kJ} / \mathrm{mol}^{-1}$. That is to say, the energy requirement for hulless barley straw pyrolysis is close to those of other agricultural residue pyrolyses. These results can be attributed to the energy requirements of the complex chemical reactions that occur during thermal conversion. Furthermore, they highlight the effect of conversion on the activation energy.

Figure 5 shows the relationship between $k_{0}$ and $V / V^{*}$, it can be found from Figure 5 and Table 4 that $k_{0}$ increased with $V / V^{*}$ within the range of $0.1-0.6$, and then decreased with $V / V^{*}$ at the range of 0.6-0.9.

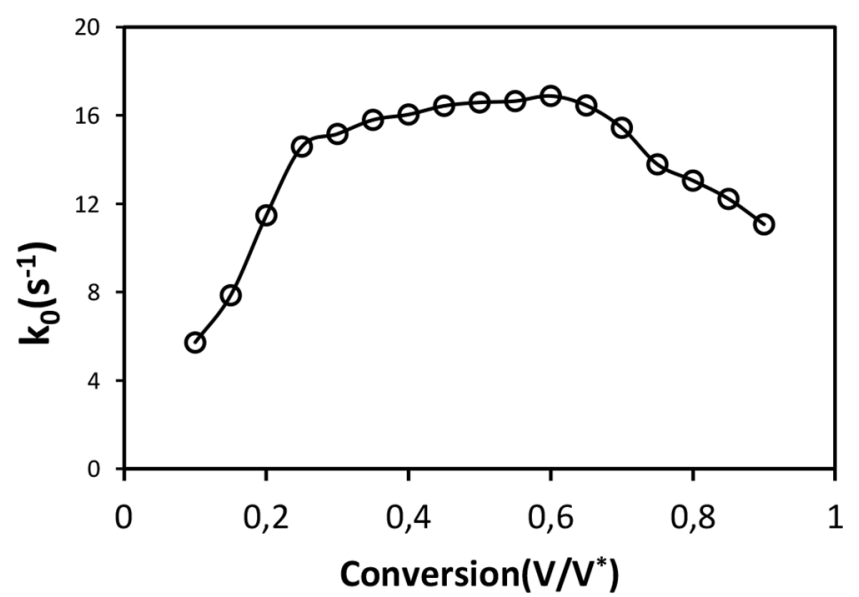

Figure 5. The plot of the relationship between $k_{0}$ and. $V / V^{*}$

An important measure used to judge the validity of the kinetic model is to examine whether the model with the kinetic parameters obtained can predict the conversion degree of the biomass pyrolysis. Utilizing the $f(E)$ and $k_{0}(E)$ obtained by DAEM, the calculated TG curves could be obtained without any mathematical fitting techniques, as shown in Fig. 6. Both the experimental curves and the predicted curves for hulless barley straw at five different heating rates correspond well to each other. Overall, the values calculated for $V / V^{*}$ by the method are in good agreement with the experimental values, demonstrating that the model has the ability to predict the pyrolysis process of the hulless barley straw biomass.

\section{Compensation effect of the kinetic parameters of pyrolytic process}

From the results of kinetic parameters, it can be found that the activation energy $(E)$ and frequency factor $\left(k_{0}\right)$ obtained under different heating rates were different. This was due to the effects of heating rates on the shapes of TG curves in the thermogravimetric method. So, it was necessary to introduce a"kinetic compensation effect" (Czajka et al., 2016).

$$
\ln k_{0}=a E+\mathrm{b}
$$

where $\mathrm{a}$ and $\mathrm{b}$ are constants.

Making plots of $\ln k_{0}$ versus $E$ at different heating rates of hulless barley straw pyrolysis as illustrated in Fig. 7, we could obtain the expression for the kinetic compensation effect of hulless barley straw pyrolysis (Eq. 7),

$$
\ln k_{0}=0.182 E+0.521, \mathrm{R}^{2}=0.977
$$



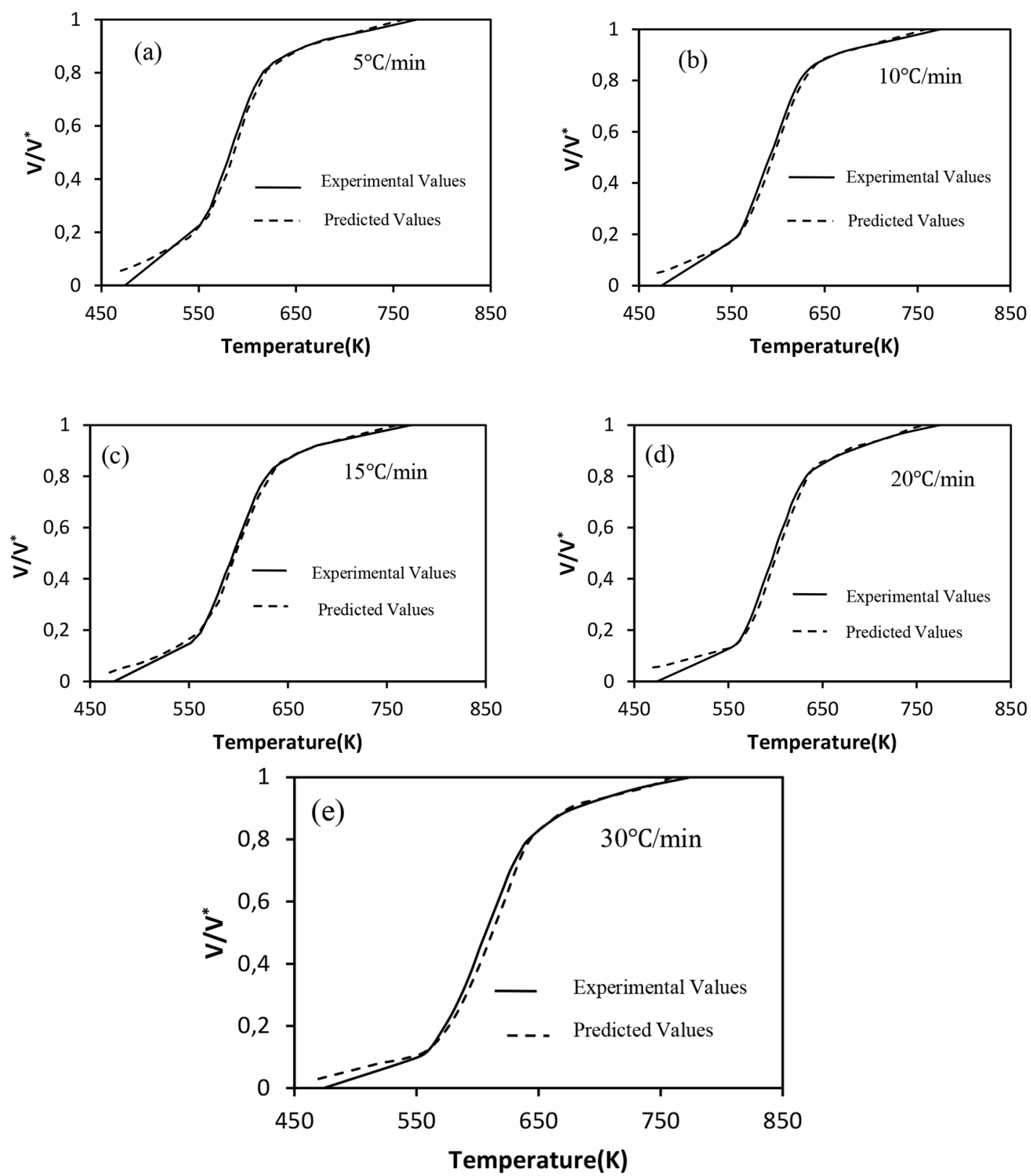

Figure 6. Comparison of experimental and predicted values for conversion degrees of hulless barley straw pyrolysis at different heating rates

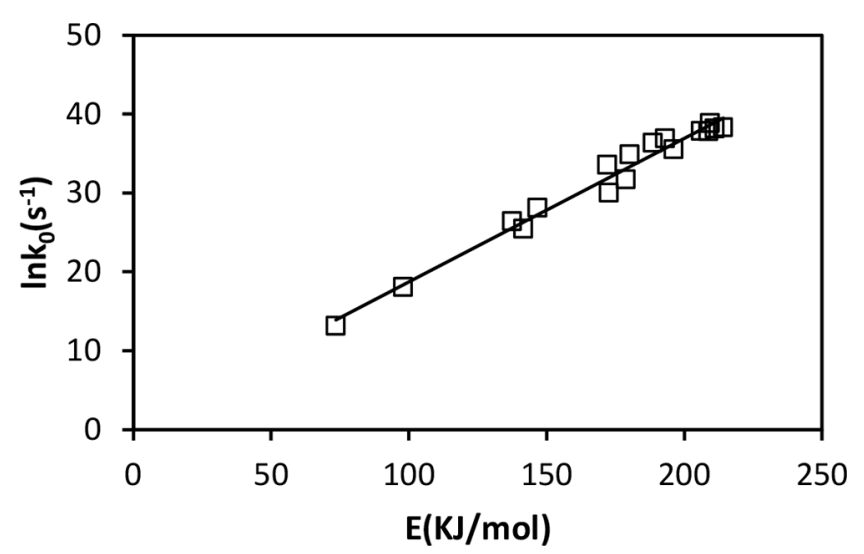

Figure 7. Relationships between $\ln k_{0}$ and $E$
The linear coefficient of correlation $\left(R^{2}\right)$ is high (0.977), indicating that the kinetic parameters $E$ and $k_{0}$ obtained exhibit the kinetic compensation effect under changing heating rates.

\section{SEM and XRD analysis of hulless barley straw de- rived biochar}

Table 2 lists the ultimate analyses of hulless barley straw derived biochars at different pyrolysis temperatures. It should be noted that the carbon content was slightly above that of its precursor in Table 1, and the contents of $\mathrm{C}$ tended to increase slightly with increasing temperature. However, $\mathrm{H}$ 
and $\mathrm{O}$ highly significantly decreased with increasing pyrolysis temperature. The contents of $\mathrm{O}$ and $\mathrm{H}$ were reduced from 19.48 and $4.5 \mathrm{wt} \%$, respectively, at $300^{\circ} \mathrm{C}$ to 14.02 and $3.30 \mathrm{wt} \%$ at $700{ }^{\circ} \mathrm{C}$. The decrease of $\mathrm{H}$ and $\mathrm{O}$ contents should result from removal of water, decomposition of lignocellulose in hulless barley straw, and more $\mathrm{CO}, \mathrm{CH}_{4}, \mathrm{CO}_{2}$ and chemical compounds containing carbon were produced.

Biochar is a solid carbon rich by-product (typically more that $60 \%$ carbon) of thermal stabilization of biomass or any other organic matter, which is usually produced at relatively low temperatures (below 700 ${ }^{\circ} \mathrm{C}$ ) (Lehmann and Joseph, 2009). The pyrolysis temperature has a great influence on the biochar property (Uchimiya et al., 2011), in order to understand the evolved porous structure of hulless barley straw derived biochar obtained at different temperatures of 300,500 and $500{ }^{\circ} \mathrm{C}$, the SEM and XRD analyses of hulless barley straw derived biochar were carried out.

The SEM images of the biochar obtained through pyrolysis of hulless barley straw are given in Figure 8 , illustrating that the pyrolysis temperature had an effect on the structure of the biochars. With the onset of the pyrolysis process, porous structures were found at the surface of the biochar formed. The porous structure of the biochar is created during pyrolysis by the production of volatile matter. As the matter escapes, pores and cracks begin to appear on the surface of the biochar. The porous structure and cracks of the resulting biochars can be clearly seen in the SEM photographs. Just like TG analysis, when the temperature exceeded $200{ }^{\circ} \mathrm{C}$, pyrolysis entered the second stage and most of the organic materials were gradually released, resulting in a large of mass loss and formation of the main pyrolytic products. After pyrolysis at $300{ }^{\circ} \mathrm{C}$ (Figure 8a), the tissue and cellulosic components of hulless barley straw biomass has not been fully degraded. Large channel-like structures proliferated on the surface of the biochar, but the remains of the vessel structure from the hulless barley straw indicated at least partial retention of the morphology of the tissue structure of the precursor plants. As the temperature increases, more volatile matter will gradually vaporize, causing the pores of biochar particles to be hollow. The surface of biochars was found to have more irregular porous structures, while at higher pyrolysis temperatures changes of surface morphology were apparent (Figures $8 \mathrm{~b}$ and c). At $500{ }^{\circ} \mathrm{C}$, the initiation of degradation and cracking starts to occur in the structure of biochar particles due to the lack of remaining fluid components. This shows that the structure of biochar degrades or ruptures due to the increase in temperature. This results in the formation of irregular structure of biochar, thus reducing the uniformity of biochar pore structure. The biochar formed at high temperature is more brittle compared to biochar formed at lower temperature and cannot withstand pressure due to its fragile structure (Claoston et al., 2014). The porous nature of the biochar structure produced at 500 and $700{ }^{\circ} \mathrm{C}$ was more prevalent, but there was more debris, as shown in Figure $6 \mathrm{~b}$ and $6 \mathrm{c}$. The biochars were found to have microporous and mesoporous structures that could strongly affect their adsorption properties.
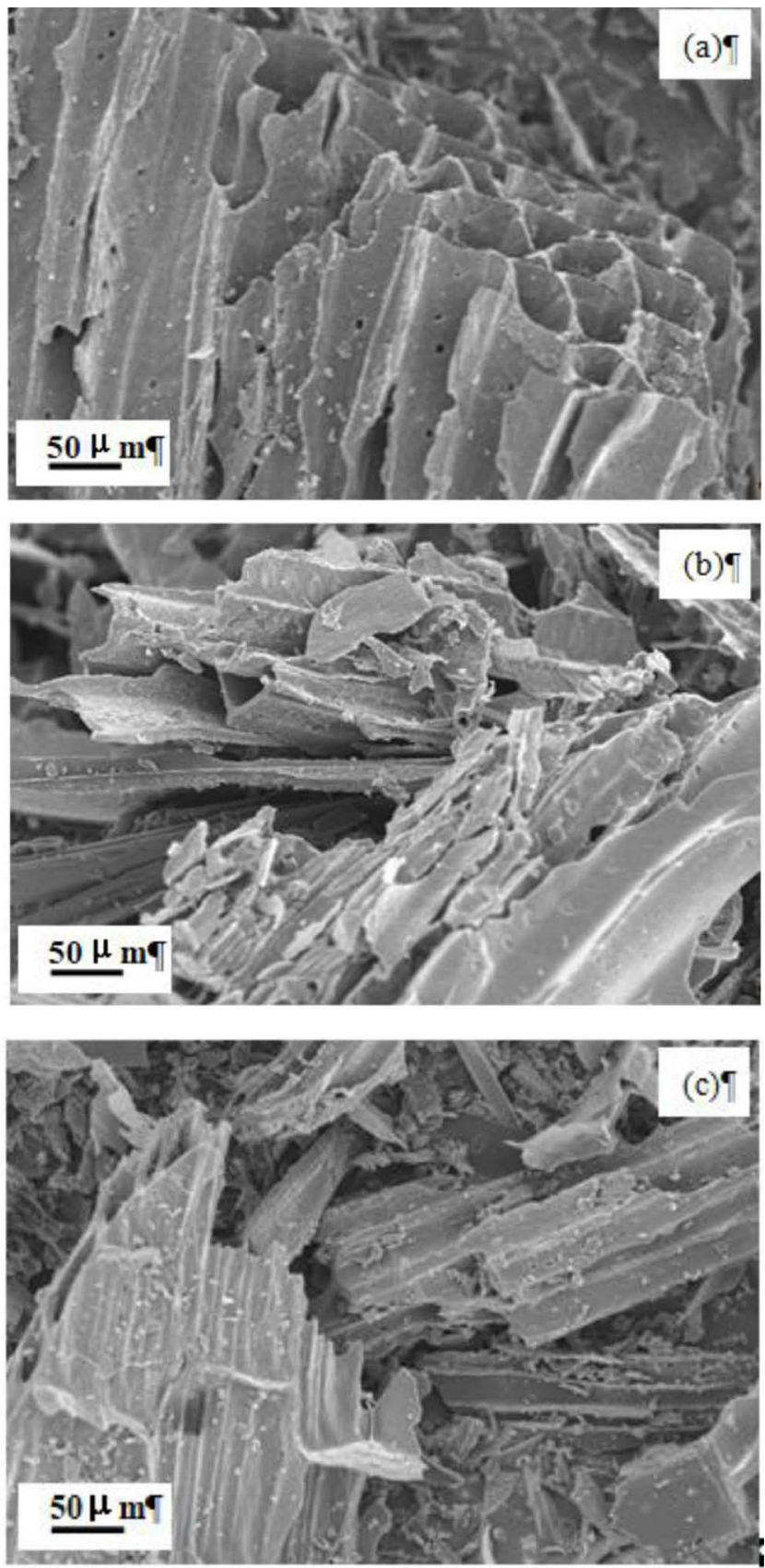

Figure 8. SEM images of biochar samples obtained at (a) $300{ }^{\circ} \mathrm{C}$, (b) $500{ }^{\circ} \mathrm{Cand}(\mathrm{c}) 700{ }^{\circ} \mathrm{C}$. 
X-ray diffraction is an applicable method to analyze the crystallinity of cellulose in biomass and the structure of bio-char. Figure 9 shows the XRD patterns of biochars obtained at different temperatures, illustrating that the patterns of the biochars show broad graphite peaks are nearly amorphous. A broad peak in the range of $20-30^{\circ}$ may indicate the early presence of a poor crystalline structure and a carbon-rich phase in these samples. These types of chars are often known as turbostratic chars, which are dominated by disordered graphitic crystallites (Uchimiya et al., 2011). There is a decrease in the intensity of this broad peak with the pyrolysis temperature, This result confirms the degradation of cellulose or structural composition of biochar sample; the peak at $20^{\circ}$ to $30^{\circ}$, as reported by Keiluweit et al. (2010), of the sample with higher temperature will progressively lose intensity and become broader, indicating a gradual decrease in cellulose. It indicates effective destruction of biomass structure at pyrolysis temperatures higher than $300^{\circ} \mathrm{C}$, which is in agreement with the results of TG analysis. The XRD spectra of the biochar showed several peaks, including the peaks at $27^{\circ}, 28^{\circ}$ and $40^{\circ}$. These results indicated that there were mineral crystals such as $\mathrm{SiO}_{2}$, $\mathrm{CaCO}_{3}$ and $\mathrm{Na}_{4} \mathrm{SiO}_{4}$ in the biochar.

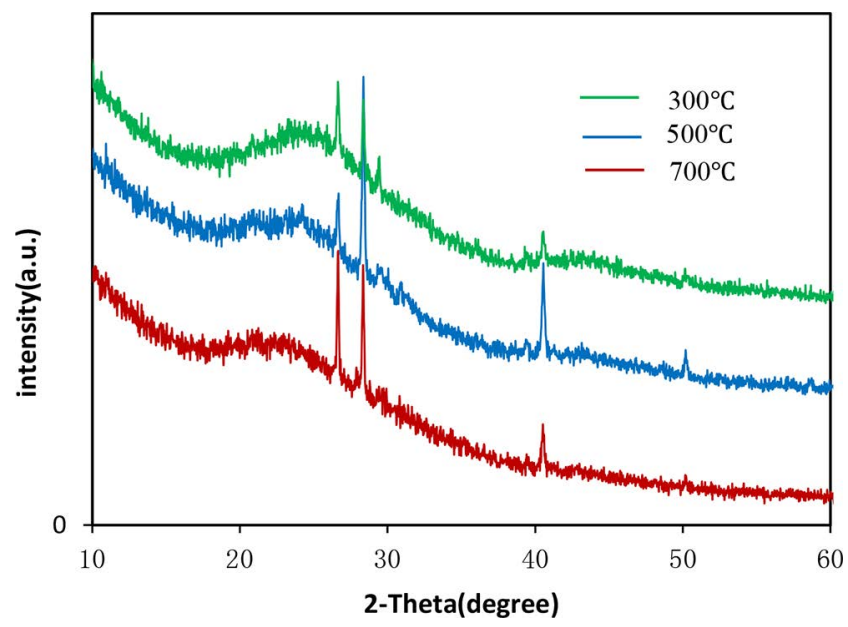

Figure 9. XRD patterns of biochars obtained at different temperatures.

\section{CONCLUSIONS}

In this study, pyrolysis of hulless barley straw was carried out in a thermogravimetric analyzer. The kinetics of hulless barley straw pyrolysis were analyzed using DAEM, and the pyrolysis product biochars were analyzed by the techniques of SEM and XRD. TG/ DTG analysis indicated that the pyrolysis process consisted mainly of an active pyrolysis stage (200-400 $\left.{ }^{\circ} \mathrm{C}\right)$ and a passive pyrolysis stage $\left(400-800^{\circ} \mathrm{C}\right)$. DAEM revealed that the activation energy $E$ ranged from 73.45 to $214.11 \mathrm{~kJ} / \mathrm{mol}$ in the conversion range of $0.10-0.55$, and changed from 214.11 to $141.55 \mathrm{~kJ} / \mathrm{mol}$ in the conversion range of $0.55-0.90$; the average value of $E$ was $172.23 \mathrm{~kJ} / \mathrm{mol}$. The values of $k_{0}$ changed greatly with $E$ values at different mass conversion. The wide $E$ and $k_{0}$ distributions obtained from the kinetic analysis are attributed to the complex chemical reactions of pyrolysis. The distributed activation energy model accurately predicted the conversion degree of the hulless barley straw pyrolysis. The kinetic parameters exhibited kinetic compensation effects and tend to promote pyrolysis as temperature increased. The porous structure of the biochar is created during pyrolysis by the production of volatile matter. The structure of the biochar degraded or ruptured due to the increase in temperature. XRD analysis confirmed that the biochar was amorphous, dominated by disordered graphitic crystallites.

\section{ACKNOWLEDGEMENTS}

The authors would like to express their gratitude for the financial supports of the National Natural Science Foundation of China (Grant No. 41261079) and the Joint Fund of National Natural Science Foundation of China and Yunnan (Grant No. U1502273).

\section{NOMENCLATURE}

$\beta \quad$ heating rate $(\mathrm{K} / \mathrm{s})$;

$V^{*} \quad$ the effective volatile content (\%);

$V$ the volatile content/volatile mass loss at temperature $T(\%)$;

$t \quad$ time (s);

$R \quad$ universal constant $(\mathrm{J} / \mathrm{mol} \mathrm{K})$;

$T$ temperature (K);

$V / V^{*}$ devolatilization rate $(\%)$

$k_{0}$ the frequency factor corresponding to the $E$ value $\left(\mathrm{s}^{-1}\right)$;

$f(E)$ a distribution curve of the activation energy;

\section{REFERENCES}

Abdel-Fattah,T. M.,Mahmoud, M. E., Ahmed, S. B., Huff, M. D., Lee, J.W. and Kumar, S., Biochar from woody biomass for removing metal contaminants and carbon sequestration. J. Ind. Eng. Chem., 22, 103-109 (2015).

Anca-Couce, A., Reaction mechanisms and multiscale modelling of lignocellulosic biomass 
pyrolysis. Prog. Energ. Combust. Sci., 53, 41-79 (2016).

Atkinson, C. J., Fitzgerald, J. D. and Hipps, N. A., Potential mechanisms for achieving agricultural benefits from biochar application to temperate soils: a review. Plant \& Soil, 337, 1-18 (2010).

Babu, B. V., Biomass pyrolysis: a state-of-the-art review. Biofuels, Bioprod. Biorefin., 2, 393-414 (2008).

Bhavanam, A. and Sastry, R. C., Kinetic study of solid waste pyrolysis using distributed activation energy model. Bioresour. Technol., 178, 126-131 (2015).

Cai, J. M., Wu, W. X. and Liu, R. H., An overview of distributed activation energy model and its application in the pyrolysis of lignocellulosic biomass. Renew. Sustain. Energy Rev., 36, 236246 (2014).

Carrier, M., Loppinet-Serani, A., Denux, D., Lasnier, J.-M., Ham-Pichavant, F., Cansell, F. and Aymonier, C., Thermogravimetric analysis as a new method to determine the lignocellulosic composition of biomass. Biomass Bioenergy, 35, 298-307 (2011).

Chen, N. W., Ren, J., Ye, Z. W., Xu, Q. Z., Liu, J. Y. and Sun, S. Y., Kinetics of coffee industrial residue pyrolysis using distributed activation energy model and components separation of bio-oil by sequencing temperature-raising pyrolysis. Bioresour. Technol., 221, 534-540 (2016).

Chiaramonti, D., Prussi, M., Buffi, M., Rizzo, A. M. and Pari, L., Review and experimental study on pyrolysis and hydrothermal liquefaction of microalgae for biofuel production, Appl. Energy, 185, 963-972 (2017).

Czajka, K., Kisiela, A., Moroń, W.,Ferens, W. and Rybak, W., Pyrolysis of solid fuels: Thermochemical behaviour, kinetics and compensation effect, Fuel Process. Technol., 142, 42-53 (2016).

Demirbas A., Effects of temperature and particle size on bio char yield from pyrolysis of agricultural residues. J. Anal. Appl. Pyrolysis, 72, 243-248 (2004).

Dhyani,V. andBhaskar, T., A comprehensive review on the pyrolysis of lignocellulosic biomass, Renewable Energy, 1-22 (2017), in press, http:// dx.doi.org/10.1016/j.renene.2017.04.035.

Dilks,R.T.,Monette, F. and Glaus, M., The major parameters on biomass pyrolysis for hyperaccumulative plants e Areview. Chemosphere, 146, 385-395 (2016).

Hassan, H., Lim, J. K. and Hameed, B. H., Recent progress on biomass co-pyrolysis conversion into high-quality bio-oil. Bioresour. Technol., 221, 645655 (2016).

Hansen, V., Müller-Stöver, D., Ahrenfeldt, J., Kai, J., Birk, U. and Hauggaard-nielsen, H., Gasification biochar as a valuable by-product for carbon sequestration and soil amendment. Biomass Bioenergy, 72, 243-248 (2015).

Huang, Y. W., Chen, M. Q. and Li, Y., An innovative evaluation method for kinetic parameters in distributed activation energy model and its application in thermochemical process of solid fuels. Thermochim. Acta, 655, 42-51 (2017).

Kan, T., Strezov, V. and Evans, T. J., Lignocellulosic biomass pyrolysis: A review of product properties and effects of pyrolysis parameters, Renew. Sustain. Energy Rev., 57, 1126-1140 (2016).

Keiluweit, M., Nico, P. S., Johnso,n M. G. andKleber, M., Dynamic molecular structure of plant biomassderived black carbon (biochar). Environ. Sci. Technol., 44, 1247-1253 (2010).

Lehmann, J. and Joseph, S., Biochar for Environmental Management: Science and Technology; Earthscan: London, U.K., 2009.

Li, D. C. and Jiang, H., The thermochemical conversion of non-lignocellulosic biomass to form biochar: a review on characterizations and mechanism elucidation. Bioresour.,Technol., in press, http:// dx.doi.org/10.1016/j.biortech.2017.07.029.

Liu, W.J., Jiang, H. and Yu, H. Q., Development of biochar-based functional materials: Toward a sustainable platform carbon material. Chem. Rev., 115, 12251-12285 (2015).

Liu, W. J., Li, W. W., Jiang, H. and Yu, H. Q., Fates of Chemical Elements in Biomass during Its Pyrolysis, Chem. Rev., 117, 6367-6398 (2017).

Miura, K., A new and simple method to estimate $f(E)$ and $k_{0}(E)$ in the distributed activation energy model from three sets of experimental data. Energ. Fuels, 9, 302-307 (1995).

Miura, K., Maki, T., A simple method for estimating $f(E)$ and $k_{0}(E)$ in the distributed activation energy model. Energ. Fuels, 12 (5), 864-869 (1998).

Murillo, J. D., Biernacki, J. J., Northrup, S. and Mohammad, A. S., Biomass pyrolysis kinetics: a review of molecular-scale modeling contributions. Brazil. J. Chem. Eng., 34, 1-18 (2017).

Navarro, M. V., Murillo, R., Mastral, A. M., Puy, N. and Bartroli, J., Application of the distributed activation energy model to biomass and biomass constituents devolatilization. AICHE Journal, 55(10), 2700-2715 (2009). 
Patel, M., Zhang, X. L. and Kumar, A., Technoeconomic and life cycle assessment on lignocellulosic biomass thermochemical conversion technologies: A review, Renew. Sustain. Energy Rev., 53, 1486-1499 (2016).

Qambrani, N. A., Rahman, Md. M.,Won, S., Shim, S. and Ra, C. S., Biochar properties and eco-friendly applications for climate change mitigation, waste management, and wastewater treatment: A review, Renew. Sustain. Energy Rev., 79, 255-273 (2017).

Sharma, A., Pareek, V. and Zhang, D., Biomass pyrolysis-A review of modelling, process parameters and catalytic studies. Renew. Sustain. Energy Rev., 50, 1081-1096 (2015).

Shen, D. K., Gu, S., Jin, B. and Fang, M.X., Thermal degradation mechanisms of wood under inert and oxidative environments using DAEM methods. Bioresour. Technol., 102 (2), 2047-2052 (2011).

Shen, J. I., Tang, H., Liu, J. Y., Wang, C., Li, Y., Ge, T. D., Jones, D. L. and Wu, J.S., Contrasting effects of straw and straw-derived biochar amendments on greenhouse gas emissions within double rice cropping systems. Agri. Ecosystems Environ., 188, 264-274 (2014).

Sonobe, T. and Worasuwannarak, N., Kinetic analyses of biomass pyrolysis using the distributed activation energy model. Fuel, 87, 414-421 (2008).

Soria-Verdugo, A., Garcia-Hernando, N., GarciaGutierrez, L. M. and Ruiz-Rivas, U., Analysis of biomass and sewage sludge devolatilization using the distributed activation energy model. Energy Conver. Manage., 65, 239-244 (2013).

Soria-Verdugo, A., Goos, E. and García-Hernando, N., Effect of the number of TGA curves employed on the biomass pyrolysis kinetics results obtained using the Distributed Activation Energy Model. Fuel Process. Technol., 134, 360-371(2015).

Statistical Bureau of Tibet Autonomous Region, National Bureau of Tibet Investigation Corps,
2015. Tibet statistical yearbook, 2015. China Statistics Press, Beijing.

Tripathi, M., Sahu, J. N. and Ganesan, P., Effect of process parameters on production of biochar from biomass waste through pyrolysis: A review. Renew. Sustain. Energy Rev., 55, 467-481(2016).

Uchimiya, M., Wartelle, L. H., Klasson, K. T., Fortier, C. A. and Lima, I. M., Influence of pyrolysis temperature on biochar property and function as a heavy metal sorbent in soil. J. Agri. Food Chem., 59, 2501-2510 (2011).

Vand, V., A theory of the irreversible electrical resistance changes of metallic films evaporated in vacuum, Proceed. Phy. Soc., 55, 222-246 (1943).

Wang, S. R., Dai, G. X., Yang, H. P., and Luo, Z. Y., Lignocellulosic biomass pyrolysis mechanism: A state-of-the-art review, Prog. Energy Combust. Sci., 62, 33-86 (2017).

Wei, O. Y., Zhao, X. C., Tysklind, M., Hao, F. H. and Wang, F.L., Optimisation of corn straw biochar treatment with catalytic pyrolysisin intensive agricultural area. Ecological Eng., 84, 278-286 (2015).

White, J.E., Catallob, W.J. and Legendre, B.L., Biomass pyrolysis kinetics: A comparative critical review with relevant agricultural residue case studies. J. Anal. Appl. Pyroly., 91, 1-33 (2011).

Yip, K., Xu, M., Li, C.Z., Jiang, S. P. and Wu, H., Biochar as a fuel: 3. Mechanistic understanding on biochar thermal annealing at mild temperatures and its effect on biochar reactivity. Energ. Fuels, 25, 406-414 (2010).

Zeng, K, Gauthier, D., Soria, J., Mazza, G. and Flamant, G., Solar pyrolysis of carbonaceous feedstocks: A review. Solar Energy. in press. http:// dx.doi.org/10.1016/j.solener.2017.05.033.

Zhang, X. S., Lei, H. W., Chen, S. L. and Wu, J., Catalytic co-pyrolysis of lignocellulosic biomass with polymers: a critical review. Green Chem., 18, 4145-4169 (2016). 